\title{
Evaluation of Circulating Immune Complexes and Anti- phospholipid Antibodies (anti Beta 2 Glycoprotein 1) in Heroin Addicts and their Clinical Significance
}

\author{
Natasa Simonovska', Andon Chibishev' ${ }^{1}$, Cvetanka Bozinovska', Ladislava Grcevska², Koco Dimitrovski ${ }^{3}$, Violeta Neceva ${ }^{3}$ \\ University Clinic of Toxicology, Clinical Centre, Skopje, R. Macedonia' \\ University Clinic of Nephrology, Clinical Centre, Skopje, R. Macedonia² \\ Institute of Transfusiology, Clinical Centre, Skopje, R. Macedonia ${ }^{3}$
}

ntroduction. Earlier studies have reported that heroin might cause the structural and antigen changes on numerous tissues, organs and subsequent development of autoimmune reactions (production of antibodies and creation of immune complexes) as a result the immunotoxic effect of heroin. The aims of our study were to: a) Evaluate CIC and antiß2GP1 in heroin addicts; b) Correlate between the values of the obtained CIC and antiß2GP1 (stratified by the duration and route of heroin application); c) Compare the CIC and antiß2GP1 in heroin addicts and the control group and d) Assess the clinical importance of CIC and antiß2GP1 in heroin addicts. Patients and methods. This was a cross-sectional study performed at the University Clinic of Toxicology and the Institute of Transfusiology, Skopje, Republic of Macedonia. Patients referred to the Clinic for clinical examinations who met the inclusion criteria were analyzed. Protocol for work was the following: 1.) detailed anamnestic data, 2.) a whole set of laboratory biochemical blood and urine analyses, 3.) examination with the Schiller's twelve-channel ECG; 4.) toxicological analyses for opioids in a urine sample; circulating immune complexes and 5.) antiphospholipid antibodies (antiß2GP1, fractions: IgA, IgG, IgM). The obtained results were statistically analyzed. Results. We included 37 heroin addicts and a control group of 27 healthy subjects. Male abusers predominated over female in - 28 (76\%) subjects; mean age being $26 \pm 5.06$. The results which refer to the increased values of circulating immune complexes have shown a high statistically significant dominance of heroin addicts, in comparison with the control group $(\mathrm{p}<0.01)$ and increased values above the reference ones of IgG antiß2GP1, alone in the group of intravenous heroin abusers $(p<0.025)$. The mean duration of the heroin use in intravenous abusers was $6.21 \pm 3.25$ years, whereas in those snorting heroin was $5.15 \pm 2.26$ years. Duration of heroin application was in a positive correlation with IgG antiß2GP1 $(p=0.35)$. Conclusions. Our data showed that heroin-dependent patients in our study had increased values of circulating immune complexes and changes in IgG and IgM antiß2GP1 with significantly increased values of IgG antiß2GP1 in the intravenous heroin abusers. The duration of heroin application is in direct proportional relationship with IgG antiß2GP1. Heroin addicts had significantly higher values of circulating immune complexes and statistically significant difference in IgG antiß2GP1, in comparison with the control group. Changes in the fractions of antiß2GP1 and CIC suggest a possible relation with the somatic changes found in heroin addicts (i.e. thrombocytopenia, reduced renal clearance, etc). KEY WORDS: HEROIN ADDICTS, CIRCULATING IMMUNE COMPLEXES, ANTIPHOSPHOLIPID ANTIBODIES (ANTI $\beta_{2} G P 1$ )

Corresponding author: Andon Chibishev, MD, PhD. University Clinic for Toxicology, Clinical Centre, Vodnjanska 17, 1000 Skopje, R. of Macedonia. Tel: +389 23211 072 +389 23237 504. E-mail:toksikourgentna@gmail.com

\section{INTRODUCTION}

The need for medical help to heroin addicts is increasing, not only as a result of an acute intoxication with opioids, but ,also as a result of a large number of somatic changes (kidney diseases, vascular disorders, etc.). The immunomodulatory effect of opioids was initially demonstrated in 1890 when Cantacuzene emphasized the effect of opioids on cellular immune suppression and decreased resistance to bacterial infection in guinea pigs treated with morphine (1). An earlier study have confirmed that heroin and its diluents might cause structural and antigen changes on numerous tissues and organs by subsequent development of the autoimmune reactions (e.g. antibody production and formation of immune complexes) resulting from heroin immunotoxic effect (2). The immunomodulatory effect of heroin and its diluents has been described to be the result, either of the direct effect of immune cells receptors or indirectly by the similar receptors of the nervous system cells (2). Different autoantibodies and immunologic abnormalities have been described in the heroin addicts. The incidence of autoantibodies and the severity of clinical symptoms are related to the duration of drug addiction and the titer of antibodies is not always related to the HIV presence or chronic viral infection. It is confirmed that the titer of antibodies is reduced after the cessation of the heroin abuse (3). 
The most common observed autoantibodies in this population were: 1 .) rheumatoid factor, 2.) anticardiolipin antibodies, 3.) antinuclear antibodies (ANA), 4.) antiphospholipid antibodies (antiß2GP1) and 5.) some other changes in the immune system (4). Antiphospholipid antibodies are a heterogeneous group of autoantibodies (i.e. a family of autoimmune and alloimmune immunoglobulins IgG, IgA, IgM or their mixture). It is a dilemma, whether they cause thrombosis, appear as a result of thrombosis or do appear accidentally. Hence, their eventual association with vascular complications in heroin addicts is yet unclear $(3,5,6)$.

As a result of changes developed in the immune system, during application of heroin and its diluents, some studies have reported the elevated circulating immune complexes titer thus attempting to highlight some conditions, which appear in heroin abusers, such as: 1.) thrombocytopenia, 2.) kidney disorders, etc. Circulating immune complexes (CIC) appear as a result of binding of an antibody to a soluble antigen. They are a constituent part of: the autoimmune diseases, SLE, cryoglobulinemia, rheumatoid arthritis, scleroderma, Sjogren's syndrome, etc. A correlation between CIC and clinical manifestations affecting the kidneys, heart and skin has been described (4). Assessment of the heroin addicts referred to our Clinic of Toxicology revealed somatic changes, which were the motive for evaluation of certain segments in the immunologic response of this group of patients and their possible interrelationship by explaining certain clinical conditions.

The aims of our study were to: a) Evaluate CIC and antiß2GP1 in heroin addicts; b) Correlate between the values of the obtained CIC and antiß2GP1 (stratified by the duration and route of heroin application) c) Compare the CIC and antiß2GP1 in heroin addicts and the control group; d) Assess the clinical importance of CIC and antiß2GP1 in heroin addicts.

\section{PATIENTS AND METHODS}

This was a cross-sectional study performed at the University Clinic of Toxicology and the Institute of Transfusiol- ogy in Skopje. Patients referred to the Clinic for clinical examinations were analyzed. Inclusion criteria for the study were the following: 1.) history of heroin abuse and 2.) confirmation of heroin abuse with toxicological analysis of the urine. Exclusion criteria was the previous history of autoimmune and infectious diseases. Data for subjects were taken from previously prepared questionnaire, along with a whole set of laboratory biochemical parametars [blood $(10 \mathrm{ml})]$ and urine analyses. Additionally, an estimated creatinine clearance rate $\left(\mathrm{eC}_{\mathrm{Cr}}\right)$ using Cockcroft-Gault formula was utilized together with the examination with the Schiller's twelve-channel ECG and toxicological urine analyses for opioids (i.e. fluorescence polarization immunoassay technique - FPIA) (7) (Institute of the Forensic Medicine, Skopje) used: a) the circulating immune complexes: b) spectrophotometric method for determination of the concentration of circulating immune complexes; c) apparatus: spectrophotometer of 740 wave-length (Institute of Transfusiology, Skopje); d) antiphospholipid antibodies (e.g. antiß2GP1, fractions: IgA, IgG, IgM with, ELISA method: ) (9) (At the Institute of Transfusiology, Skopje) a circulating immune complexes and antiß2GP1 were examined in a blood sample $(5 \mathrm{ml})$. Subjects participating in this study gave their written informed consent.
The statistical analysis of the results was performed by the descriptive and analytical statistical methods. Descriptive methods included: 1.) the arithmetic mean; 2.) standard deviation; 3.) frequency and 4.) cross tabulations. For testing of the null hypothesis, the following analytical statistical tests were used: 1.) Fischer's exact test, 2.) Mann-Whitney U-test of inversion and 3.) Spearman's coefficient of nonparametric correlation. Probability levels $(\mathrm{p})$ were $\mathrm{p}=0.05$ and $\mathrm{p}=0.01$. The entire statistical analysis was done with the statistical program SPSS, version 14.00, Chicago, IL.

\section{RESULTS}

We included 37 heroin addicts; where the male abusers were predominant with - 28 (76\%) subjects and the mean age of $26 \pm 5.06 \mathrm{y}$. The youngest abuser was 19 years old and the oldest 47 years. The control group consisted of 27; (i.e. age - and sex-matched healthy subjects). The examined immunologic parameters in the control group confirmed their reference values as per healthy population. Out of the total number of examined heroin addicts, 24 injected heroin intravenously and 13 by snorting. The mean duration of heroin

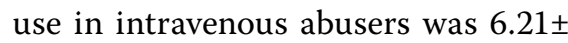
3.25 years, whereas, in those snorting heroin it was $5.15 \pm 2.26$ years. The du-

\begin{tabular}{|l|l|l|l|}
\hline $\begin{array}{l}\text { Examined } \\
\text { parametersn=37 }\end{array}$ & $n$ & $\mathrm{p}$ & Associated cl. conditions \\
\hline $\mathrm{CIC}$ & $21 / 37$ & $\mathrm{p}<0.01$ & $\begin{array}{l}\text { Thrombocytopenia } \mathrm{n}=2 \mathrm{X}=62,5 \times 10^{9} / \mathrm{l} \text {; Proteinuria } \\
\mathrm{n}=11 \mathrm{X}=0,32 \mathrm{~g} / \mathrm{l} ; \text { decreased kidney clearance } \mathrm{n}=3 \\
\mathrm{GFR}=75 \mathrm{ml} / \mathrm{min} ;\end{array}$ \\
\hline antiß2GP1lgA & $/$ & $\mathrm{p}>0.05$ & $/$ \\
\hline antiß2GP1lgG & $10 / 37$ & $\mathrm{p}<0.025$ & Vascular changes \\
\hline antiß2GP1lgM & $2 / 37$ & $\mathrm{p}>0.05$ & $/$ \\
\hline
\end{tabular}

TABLE 1. Heroin addicts with increased values of CIC and antiß2GP1 fractions: IgA, IgG, IgM (Fischer's exact test) and associated clinical conditions.. CIC (circulating immune complexes), antiß2GP1 (anti-beta 2 glycoprotein 1), n (number of subjects), proteinuria ref.v: 0,1g/l; Trombocytopenia ref.v: 140-340 x109/I

\begin{tabular}{|l|c|c|c|c|c|c|c|c|}
\hline & \multicolumn{2}{|c|}{ CIK } & \multicolumn{2}{c|}{ Anti B2GP1 IgA } & \multicolumn{2}{c|}{ Anti B2GP1 lgG } & \multicolumn{2}{c|}{ Anti B2GP1 lgM } \\
\hline & $\mathrm{n}$ & $\mathrm{X} \pm \mathrm{SD}$ & $\mathrm{n}$ & $\mathrm{X} \pm \mathrm{SD}$ & $\mathrm{n}$ & $\mathrm{X} \pm \mathrm{SD}$ & $\mathrm{n}$ & $\mathrm{X} \pm \mathrm{SD}$ \\
\hline $\mathrm{i} / \mathrm{v}$ & 18 & $0.10 \pm 6.2$ & 0 & $/$ & 10 & $25.6 \pm 3,53$ & 2 & $21.0 \pm 0.0$ \\
\hline Snor. & 03 & $0.07 \pm 2.3$ & 0 & $/$ & 0 & $/$ & 0 & $/$ \\
\hline $\mathrm{p}$ & $\mathrm{p}>0.05$ & & $\mathrm{p}>0.05$ & & $\mathrm{p}<0.025$ & & $\mathrm{p}>0.05$ & \\
\hline
\end{tabular}

TABLE 2. Serum concentration of relevant immunologic parameters ( $C I C$ and antiß2GP1 fractions: $\lg A$, IgG, IgM, for values above the control ones), according to the route of heroin application. CIC (circulating immune complexes, ref. v.: 0.00-0.05 g/l), antiß2GP1 (anti-beta 2 glycoprotein 1) fractions: IgA, lgG, IgM (ref. v.: 0-20 SAU), $\mathrm{n}$ (number of subjects); X (mean value); SD (standard deviation); i/v (intravenous application); snor. (snorting) 


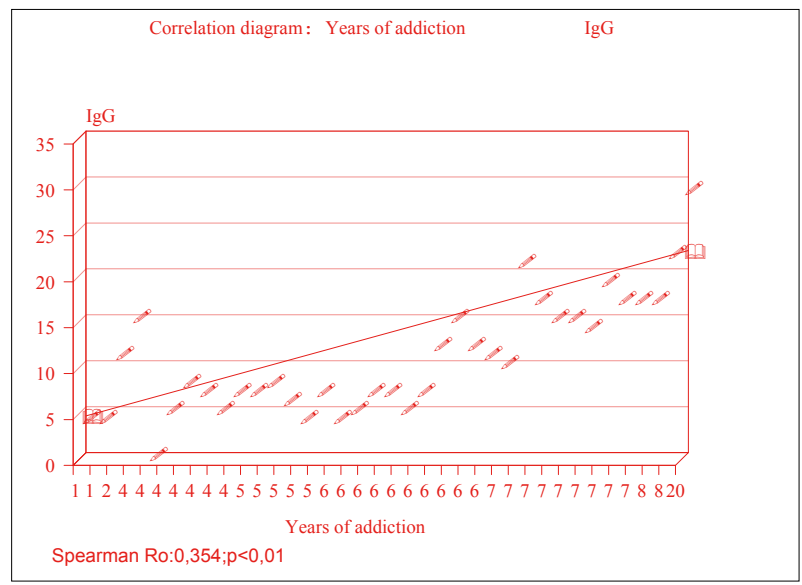

FIGURE 1. Correlation diagram ( years of addiction)

ration of heroin application positively correlated with IgG antiß2GP1.

\section{DISCUSSION}

As reported in the literature, the heroin and its diluents may cause the immunologic abnormalities, in heroin addicts, as reflected as the presence of different autoantibodies. By reporting their experiences, the authors emphasize the clinical importance of these immunologic changes, in heroin addicts and at the same time they give a possible explanation about some of the somatic changes that appear. Crowe et al. stated that kidney complications might develop in heroin addicts, but their pathogenesis is still unclear (10). Earlier studies reported that heroin or some of its diluents acted as an antigen, leading to renal deposition of immune complexes in the kidney (10). Recent studies have shown that morphine may have a direct effect on the glomerulus, causing proliferation of fibroblasts and a decreased degradation of type IV collagen (10). Manner et al., in his study presented his experience of finding renal amyloidosis in heroin addicts, as verified by the renal biopsy and suggested that one should always have in mind the renal amyloidosis in chronic heroin addicts with proteinuria and renal impairment $(11,12)$. Similar experience was published by Connoly at al., in his study (13). In our group of 37 heroin addicts, 21 had increased values of circulating immune complexes above the control values. In three of them, a reduced renal clearance was registered, whereas in 11 proteinuria was observed. Savona et al., described an autoimmune thrombocytopenia, in heroin-dependent in- dividuals, thus suggesting a new immunologic disorder in the blood cells. Elevated circulating immune complexes were noticed in 33 patients (14). Moss at al., pointed out that heroin may be a possible cause for immune thrombocytopenia and he anticipated that platelets may be rapidly removed from the circulation, as a result of the attached "drug-antibody" immune complexes (15). In our group of 21 heroin-addicted subjects with elevated values of circulating immune complexes above the reference level, thrombocytopenia was observed only in 2 patients.

Analysis of antiß2 GP1 was also performed in our examined group. Increased values above the reference levels were detected in the IgG fraction, thus revealing that two of the patients had thrombosis of the legs in the past. In one of them, the increased size of right lower limb was noticed and the thorough examination excluded the thrombosis and other evident vascular disorders. Eight months later, the follow-up assessment of these patients detected thrombosis in the left lower limb in one of them. Nikolova at al., in her study of 10 patients found a high ANCA titer in two, elevated ANA titer in four (e.g. two of whom were antiHCV positive) and positive IGM anticardiolipin antibodies in 3 heroin addicts (i.e. two of whom had biopsyproven chronic tubulo-interstitial nephritis) (3). Four patients in the same study had elevated titer of antiphospholipid antibodies (antiß2GP1). Such elevated antiß2GP1 titers were described by several authors, in association with arterial or venous thrombosis or without thrombotic changes (3). It has been reported that IgG anti $\beta 2 \mathrm{GP} 1$ is closely associated with venous and arterial thrombosis (16). Over a longer followup of these patients or after the cessation of heroin abuse these antibodies have been removed. Nikolova et al., reported that the autoantibody incidence corelate with the duration of heroin addiction (3). Our results have confirmed this positive correlation with the duration of heroin application for IgG antiß2GP1, alone.

\section{CONCLUSION}

Our data showed that heroin-dependent patients, in our study, had increased values of circulating immune complexes and changes in IgG and IgM antiß2GP1, with significantly increased values of IgG anti 32 GP1 in the intravenous heroin abusers. The duration of heroin application is in direct proportional relationship with IgG antiß2GP1. Heroin addicts had significantly higher values of circulating immune complexes and statistically significant difference in IgG antiß2GP1 in comparison with the control group. Changes in the fractions of antiß2GP1 and CIC suggest a possible relation with the somatic changes found in heroin addicts (thrombocytopenia, reduced renal clearance, vascular disorders, etc.).

\section{REFERENCES}

1. Ramsin B,Trescot A, Datta S, Buenaventura R, Adlaka R, Sehgal N et al. Opioid Complications and Side Effects. Pain Physician. Opioid Special Issue. 2008; 11:105-120.

2. Friedman H, Newton C, Klein T. Microbia Infections, Immunomodulation and drugs of abuse. Clin Microbiol Rev. 2003; 16: 209-219.

3. Nikolova M, Ljubomirova M, Iliev A, Krasteva $\mathrm{R}$, Andreev E, Radenkova J et al. Clinical Significance of Antinuclear Antibodies, Antineutrophil Cytoplasmic Antibodies and Anticardiolipin Antibodies in Heroin Abusers. IMAJ. 2002; (Suppl): 908-10.

4. Cohen SL, Fischer C, Mowbray JF et al. Circulating and deposited immune complexes in renal disease and their clinical correlation. in renal disease and their clinical
J.Clin.Path. 1979; 1135-1139.

5. Ancsi B, Vander IK, Bertina RM. $\beta 2$ glycoprotein I deficiency and risk of thrombosis Thromb. Haemost. 1992; 67: 649-653.

6. Bick RZ, Baker WF. Antiphospholipid syndrome and thrombosis. Semin. Thromb. Haemost. 1999; 25: 333-50.

7. Wang et al. Fluorescence polarization immunoassay. United States Patent. 1986.

8. Jolley ME. Fluorescence polarization immunoassay for determination of therapeutic drug level in human plasma. J Anal Toxicol. 1081; 5: 236-40.

9. Lequin RM. Enzyme immunoassay (EIA). Enzyme-Linked immunosorbent Assay (ELISA) zyme-Linked immunosorbent Assay (ELISA).

10. Crowe AV, Howse M, Bell GM, Henry JA. Substance abuse and the kidney. Q J Med. 2000; 93: 147-152.

11. Piyarat G, Tunda S, Naiphinich K, Thongchai $\mathrm{U}$. Alterations of Immune Functions in Heroin Addicts and Heroin Withdrawal Subjects. Pharmacol Exp Ther. 1998; 286: 883-9.

12. Manner I, Sagedal S, Roger M, Os I. Renal amyloidosis in intravenous heroin addicts with nephritic syndrome and renal failure. Clin Nephrol. 2009; 72: 224-8.

13. Connoly JO, Gillmore JD, Lachmann HJ, Davenport A, Hawkins PN, Woolfson RG. Renal amyloidosis in intravenous drug users. Q J Med. 2006; 99: 737-742.

14. Savona S, Nardi MA, Lennete ET, Karpatkin S. Thrombocytopenic purpura in narcotic S. Thrombocytopenic purpura in narcotic

15. Moss RA. Drug-induced immune thrombocytopenia. Am J Hematol. 1980; 9(4: 439-46.

6. Cervera R. Antiphospholipid Syndrome: clinical and immunologic manifestations and patterns of disease expression in a cohort of 1000 patients. Arthritis Rheum. 2002; 46: 1019. 